\title{
Os Enunciados de Comando da Prova do EDETM e sua Relação com Competências e Capacidades para a Resolução de Situações-Problema
}

\author{
Maria Ilza ZIRONDI \\ (CAPES-UEL) \\ Elvira Lopes NASCIMENTO
}

(UEL)

\begin{abstract}
Resumo: Este trabalho é uma reflexão sobre a Prova do ENEM como um gênero textual de avaliação, visto não apenas como uma construção estrutural codificada por elementos da língua com mero propósito de avaliação de "competências" leitoras e produtoras de texto "apreensíveis" nas respostas dadas às questões, mas como uma relação dos múltiplos aspectos que envolvem a ação de linguagem de um agente, que se dá sob a forma de um texto - materialidade empírica, cujas propriedades organizacionais internas são determinadas por essa ação que o gerou. Disponível no arquitexto (BRONCKART, 2006, p. 145) de nossa comunidade, buscamos analisar sob a perspectiva do interacionismo sócio-discursivo a complexidade das operações de linguagem que em grande número permeiam a Prova e configuram o gênero. Considerando que o ENEM avalia até certo ponto o ensino, pressupomos que, buscar uma melhor percepção dos mecanismos operantes entre ensino/aprendizagem e avaliação, reveste-se de grande importância social, pois pode significar iniciativas para revisão e reavaliação dos PCNEM, do material fornecido pelo Plano Nacional do Livro Didático (PNLD) e da própria estruturação curricular elaborada pelas escolas que desenvolvem trabalho com ensino médio. Palavras-chave: prova do ENEM; interacionismo sócio-discursivo; avaliação
\end{abstract}

Abstract: This work presents some reflections on the ENEM exam as an evaluation textual genre, seen not only as a structural construction 
codified by language elements with the mere purpose of evaluating the reading and text-producing "competences" "apprehensible" in the answers given to the questions, but as the locus of a relationship of multiple aspects that encompass an agent's language action, which happens by means of a text - empirical materiality, whose internal organizational properties are determined by this generating action. Available in the architext (BRONCKART, 2006, p. 145) of our community, we intend to analyze from the perspective of the sociodiscursive interactionism, the complexity of the language operations that abundantly permeate the exam and constitute the genre. Considering that the ENEM evaluates teaching to a certain extent, we presume that, to search for a better perception of the operating mechanisms between teaching/learning and evaluation is of great social importance as it may foster initiatives of revision and reassessment of the PCNEM, of the material provided by the National Plan of Textbooks (Plano Nacional do Livro Didático -PNLD) and of the curricular structure designed by the schools that work with high school students.

Keywords: ENEM exam; socio-discursive interactionism; evaluation.

Resumem: Este trabajo propone una reflexión sobre el ENEM como un género textual de evaluación, considerado no solamente como una construcción estructural codificada por elementos de la lengua con un simple propósito de evaluación de "competencias" lectoras y productoras de texto "aprehensibles" en las respuestas ofrecidas por las cuestiones, pero como una relación de los múltiples aspectos que involucran la acción de lenguaje de un agente, que ocurre bajo la forma de un texto - materialidad empírica, cuyas propiedades organizacionales internas son determinadas por esa acción que lo generó. Disponible en el arquitexto (BRONCKART, 2006, p. 145) de nuestra comunidad, buscamos analizar bajo la perspectiva del interacionismo sociodiscursivo la complejidad de las operaciones del lenguaje que aparecen en gran número en el Examen y configuran el género. Considerando que el ENEM evalúa hasta cierto punto la enseñanza, se supone que buscar una mejor percepción de los mecanismos operativos entre enseñanza/ aprendizaje y evaluación, se reviste de gran importancia social, pues puede significar iniciativas para la revisión y reevaluación de los PCNEM, del material ofrecido por el Plan Nacional del Libro Didáctico (PNLD) 
y la propia estructuración curricular elaborada por las escuelas que desarrollan un trabajo con la enseñanza media.

Palabras-clave: examen del enem; interacionismo socio-discursivo; evaluación

\section{Introdução}

Este trabalho é uma reflexão sobre a Prova do ENEM, um dos mecanismos de avaliação utilizado pelos órgãos governamentais responsáveis pela política educacional brasileira, para avaliar a qualidade do ensino adquirido ao longo do Ensino Fundamental e término do Médio. Além disso, esse teste serve como "termômetro" para o aluno analisar os próprios conhecimentos e habilidades (de leitura e escrita) adquiridos ao longo de sua vida escolar. Essa pesquisa, cujo foco é analisar a Prova do ENEM como um gênero textual disponível no arquitexto (BRONCKART, 2006, p. 145) de nossa comunidade, busca analisar a complexidade das operações de linguagem que em grande número permeiam a Prova e configuram o gênero.

A prova do ENEM faz parte do conjunto de textos produzidos para os contextos de avaliação nacional, e apresentam características que os distinguem das "provas" utilizadas pela escola para avaliar o ensino/aprendizagem da língua materna e das múltiplas disciplinas que compõem o currículo básico escolar. $O$ texto que constitui a Prova espera que o candidato (ZIRONDI; NASCIMENTO, 2006) ${ }^{1}$ direcione e canalize a sua reflexão para os propósitos e objetivos expressos nos enunciados de comando da Prova. Ou seja, antes de responder a uma questão, pressupõe-se que os estudantes, além de terem que compreender o texto que dá origem à questão como uma prática social no contexto particular de produção, circulação e recepção e serem capazes de reconhecer as características de sua infraestrutura textual, possam extrapolar essas capacidades para buscar a função do texto desencadeador da questão em relação aos objetivos dos enunciados de comando da Prova, o que exige do indivíduo avaliado

\footnotetext{
${ }^{1}$ Neste trabalho são apresentadas as características do plano textual global (para da infra-estrutura textual, BRONCKART, 1999) que caracterizam e definem o gênero.
} 
a captura de uma nova dimensão do contexto de produção que agora os constitui.

Essa Prova, vista como a configuração de uma ação de linguagem que tem o propósito de avaliar e julgar as capacidades e/ou competências de um grande conjunto de sujeitos, têm características contextuais e arquitetônicas próprias. Isso torna a Prova do ENEM um texto diferente das provas ou testes que configuram a ação de linguagem de um sujeito-avaliador-julgador em uma sala de aula particular, que tem um número de alunos com características particulares.

Responsáveis pela organização curricular, as políticas educacionais são voltadas para a qualificação da educação básica. Os princípios e critérios organizacionais desses documentos têm a finalidade de proporcionar, ao aluno, a assimilação das múltiplas funções da linguagem (apreensão e uso) das formas escritas usuais, orais ou normativas, em suas práticas de linguagem. No ENEM, no tocante à língua portuguesa, o foco de avaliação ocorre na compreensão de leitura, embora solicite dos alunos a produção textual que demonstra de maneira empírica o que sabem e aprenderam com o ensino da língua materna, centraliza nas questões objetivas a avaliação da qualidade do ensino-aprendizagem adquirido pelos aprendizes. Além disso, compreensão e produção de textos são aspectos convergentes no que tange ao uso da linguagem, assim, a avaliação assegura um tratamento interdisciplinar tanto para a produção como para a resolução de situação-problema.

Considerando que o ENEM visa à avaliação do ensino, assim como outros processos de avaliação como o vestibular, dos efeitos retroativos (SCARAMUCCI, 2004) que podem se refletir na mudança de conduta, valoração e percepção de alunos e professores, sobretudo do ensino médio, acreditamos que a tentativa de buscar uma melhor percepção dos mecanismos operantes entre ensino/ aprendizagem e avaliação do ENEM se reveste de grande importância social, pois isso pode implicar iniciativas para revisão e reavaliação dos Parâmetros Curriculares Nacionais para o Ensino Médio (PCNEM), do material fornecido pelo Plano Nacional do Livro Didático (PNLD) e da própria estruturação curricular elaborada pelas escolas que desenvolvem trabalho com EM.

Como os gêneros textuais, organizações lingüísticoenunciativas (BAKTHIN, 1979) devem funcionar como instrumento de 
mediação da ação pedagógica (SCHNEUWLY, 1994/2004), e, portanto, constituindo os objetos de ensino (PCNEM, 1997), esta pesquisa se insere no grupo de pesquisas que propõem um enfoque dialético dos gêneros textuais, através dos quais esperamos avançar na busca da compreensão das práticas linguageiras situadas, ou seja, os textos/discursos - instrumentos principais do desenvolvimento humano.

Como o foco de nossa pesquisa é o trabalho didático a partir dos gêneros textuais, buscamos averiguar como a prova do ENEM se configura como um gênero textual, visto não apenas como uma construção estrutural codificada por elementos da língua com mero propósito de avaliação de "competências" leitoras e produtoras de texto "apreensíveis" nas respostas dadas às questões, mas como uma relação dos múltiplos aspectos que envolvem a ação de linguagem de um agente, que se dá sob a forma de um texto - materialidade empírica, cujas propriedades organizacionais internas são determinadas por essa ação que o gerou.

Buscamos, assim, constatar os efeitos de sentido produzidos pelo enunciador num processo que se dá pela relação interativa e situacional em relação às situações de uso da linguagem nesse gênero em especifico, se constituindo como uma "teia" que associa as múltiplas vertentes que indexam o gênero a sua função social específica. Para discutirmos sobre esses aspectos, primeiramente apresentaremos sucintamente a teoria sócio-discursiva proposta por Bronckart para explicar como ela nos fornece elementos que contribuem para a análise; em seguida vamos refletir sobre os propósitos de utilizar as situações-problema para o desenvolvimento e avaliação de competências; por último, apresentamos a análise e discussão dos enunciados de comando das provas do ENEM: sua configuração, estrutura e articulação para conduzir o inscrito a realizar tarefas que possibilitam, de um lado, a avaliação proposta pelos órgãos governamentais e, de outro, a auto-avaliação realizada pelo aluno.

\section{Interacionismo Sócio-Discursivo para Explicar as Ações de Linguagem}

Fundamentamos a base de nossa análise no Interacionismo Sócio-discursivo proposto por Jean Paul Bronckart. Epistemologicamente, o termo interacionismo social é uma adesão 
do autor à tese de que "as propriedades específicas das condutas humanas são o resultado de um processo histórico de socialização, possibilitado especialmente pela emergência e pelo desenvolvimento dos instrumentos semióticos" (BRONCKART, 1999, p. 21-22). Assim:

A posição interacionista implica, portanto, a idéia de que é ilusório tentar interpretar as condutas humanas em sua especificidade, seja por referência direta às propriedades do substrato neurobiológico humano (direção tomada pelo cognitivismo e pelas neurociências), seja como o resultado da acumulação de aprendizagens condicionadas pelas restrições de um meio preexistente (tese fundadora do behaviorismo). Levando a sério a historicidade do ser humano, a investigação interacionista se interessa, em primeiro lugar, pelas condições sob as quais, na espécie humana, se desenvolveram formas particulares de organização social, ao mesmo tempo que (ou sob o efeito de) formas de interação de caráter semiótico. A seguir, desenvolve uma análise aprofundada das características estruturais e funcionais dessas organizações sociais, assim como dessas formas de interação semiótica. Enfim, trata dos processos filogenéticos e ontogenéticos pelas quais essas propriedades sociossemióticas tornam-se objeto de uma apropriação e de uma interiorização pelos organismos humanos, transformando-os em pessoas, conscientes de sua identidade e capazes de colaborar com as outras na construção de uma racionalidade do universo que os envolve.

E é sócio-discursivo à medida que adere às idéias vygotskyanas de que o homem, enquanto organismo vivo, é dotado de propriedades biológicas e comportamentos, além disso, é um organismo consciente que se sabe possuidor de capacidades psíquicas que as idéias, os projetos e os sentimentos traduzem. Desta forma, no conjunto de suas capacidades psicológicas, agentes particulares agem para atingir seus objetivos específicos e as suas ações são reveladas (ou revelam) as dimensões sociais e discursivas em funcionamento dentro dos grupos humanos. Essa atividade, que é propriamente de linguagem, é organizada em discursos ou em textos que se diversificam em gêneros.

Bronckart busca aportes epistemológicos e teóricos de diferentes vertentes das Ciências Humanas que possam vir a contribuir para elucidação e compreensão dos elementos que constituem as 
atividades de linguagem, os discursos e o desenvolvimento humano, traduzidos nos gêneros textuais, sejam elas da área da lingüística, filosofia, artes, sociologia, psicologia etc., afinal as suas preocupações centrais são, de um lado, "as das relações de interdependência que se instauram e se desenvolvem entre os aspectos fisiológicos, cognitivos, sociais, culturais, lingüísticos, do funcionamento humano; de outro lado, os aspectos dos processos evolutivos e históricos pelos quais essas diferentes dimensões foram engendradas e co-construídas" (BRONCKART, 2006a, s/p).

Aliados à base Sócio-interacionista, Bernard Schneuwly e Joaquim Dolz centram suas reflexões na elaboração de princípios e métodos em didática, principalmente, relacionados ao ensinoaprendizagem de línguas e com a formação do professor: a transposição didática, as interações em sala de aula e a construção dos objetos a serem ensinados. Para isso, propõem a análise curricular, pois os conteúdos disciplinares são definidos em função das capacidades do aprendiz e das experiências a ele necessárias (DOLZ; SCHNEUWLY, 2004, p. 42). Ainda, segundo eles, as principais funções de um currículo são de descrever e explicitar o projeto educativo em função das finalidades da educação e das expectativas da sociedade; instrumentalizar as práticas de professores; considerar as condições para realização dessa prática; analisar as condições de exeqüibilidade. A grade curricular será, assim, a norteadora para que a aprendizagem ocorra.

A maestria de um gênero aparece co-relacionada à maestria de situações de comunicação e é definida por três dimensões essenciais: o conteúdo, a estrutura e as unidades lingüísticas que irão remeter para o que os autores chamam de capacidades de linguagem, que são aptidões requeridas do aprendiz para a produção de um gênero numa situação de interação determinada. Portanto, para a produção de um gênero textual, o aprendiz mobiliza cognitivamente:

- Capacidades de ação: adaptação às características do contexto e do referente;

- Capacidades discursivas: utiliza-se de modelos discursivos;

- Capacidades lingüístico-discursivas: domínio das capacidades psicolingüísticas e as unidades lingüísticas.

Para resolver as questões da Prova do ENEM, pressupõese que o aluno já tenha adquirido ao longo de sua vida escolar, nos níveis fundamental e médio, as capacidades de linguagem necessárias para 
contextualizar, discursar, compreender o código lingüístico e fazer inferências para resolver as situações-problema. As etapas da formação escolar devem ser pautadas no ensino por competências, isto é, os conteúdos devem ser vistos como um meio para o desenvolvimento das competências e não como um fim. Ou seja, a finalidade de uma atividade, o conteúdo, devem ser vistos como um objeto do saber (diferente, portanto da noção de capacidade) o que significa que a noção de competência pode ser explicada, grosso modo, como uma aptidão para fazer algo, exercício de uma atividade. Para falarmos de competência nos apoiaremos em Perrenoud, Macedo et al. (2002); PCNEMs; Kleiman (2006); Pinheiro e Burini (2004), entre outros.

A teoria do Interacionismo sócio-discursivo para explicar os gêneros de textos e tipos de discurso em interações que promovem o desenvolvimento humano é proposta por Bronckart (2006a, p.121), no que diz respeito à analise do funcionamento da linguagem e da gênese das condutas humanas, assim como às atividades de linguagem nos processos de organização social e à história das interações entre os homens. Na busca de reorganizar a problemática psicológica das atividades de linguagem, o autor propõe a articulação de três níveis de analise:

$1^{\circ}$ nível: refere-se à vida social, os pré-construtos históricos:

- As formações sociais e os fatos sociais (instituições, valores, normas);

- As atividades coletivas gerais (relações entre indivíduos e seu ambiente);

- As atividades de linguagem (uso da língua natural materializado em diversos tipos de textos);

- Mundos formais (estrutura de conhecimentos coletivos).

$2^{\circ}$ nível: refere-se aos processos de mediação formativa:

- Conjunto de processos de controle e avaliação das condutas verbais e não verbais, conjunto dos préconstruídos no ambiente sociocultural, desde o nascimento; 
- Controle e avaliação das condutas verbais e não verbais dos processos educativos explícitos que se realizam, principalmente, nas instituições escolares.

$3^{\circ}$ nível: refere-se aos efeitos que as mediações formativas exercem sobre os indivíduos:

- Às condições de transformação do psiquismo sensóriomotor herdado em um pensamento consciente, fundador da pessoa, resultado da interiorização das propriedades estruturais e funcionais dos signos lingüísticos;

- Às condições de desenvolvimento das pessoas e de suas capacidades ativas, no âmbito de transações entre as representações individuais e as representações coletivas, veiculadas pelos pré-construídos.

Nosso trabalho, que também se inscreve nesse mesmo campo das ciências do texto, visa, por meio desse esquema, a buscar uma compreensão dos mecanismos de produção e de interpretação da Prova do ENEM, como entidade verbal e, assim, contribuir para a transformação permanente das pessoas agentes, e, ao mesmo tempo, dos fatos sociais.

Numa visão sócio-interacionista, tentaremos discutir a problemática que envolve o gênero de texto de avaliação (Prova do ENEM) em seus aspectos psicológicos, cognitivos, sociais, culturais e lingǘsticos do funcionamento humano de um lado, e de outro, a do processo histórico pelo qual essas dimensões foram engendradas (BRONCKART, 2006b). Como segmento da atividade coletiva, o agir coletivo permite a mobilização de signos organizados em textos que admitem a construção de mundos de conhecimentos autônomos em relação às circunstâncias individuais da ação de linguagem. Por isso, neste trabalho nos propomos esboçar formas interpretativas para essas ações e a atuação dos atores responsáveis por esse agir da linguagem.

Baseados na proposição de que toda produção verbal situada é um texto, admitimos a "idéia de que certos tipos de textos são mais simples que outros, ou repousam sobre operações linguageiras menos numerosas e menos complexas, ou ainda que constituem uma espécie de tipos ideais". Para Bronckart os "tipos ideais" de textos são 
qualificados como standards, pois colocam em evidência regras básicas de organização de todos os textos. Contudo, há, “outros" tipos de textos, mais complexos, que exigem a captura de uma nova dimensão do contexto de produção, pois se excedem caracterizando-se pelas transformações das regras de base dos textos standards. Para dominar as suas regras de funcionamento, antes, os estudantes devem dominar as regras de base comuns, e da mesma forma, os produtores dos textos não standards devem dominar as regras de textos standards para, em seguida, transformá-las em função de seus próprios objetivos.

Consideramos o texto da Prova do ENEM como um texto não-standard, mas que faz uso ou é construído sobre regras de funcionamento comuns que são (pelo menos deveriam ser) do conhecimento (domínio) dos alunos. O que buscamos nessa análise é esquadrinhar uma compreensão dessa atividade de linguagem e sua complexa elaboração vinculada a objetivos e a propósitos específicos que podem ser relacionados a um contexto histórico (de produção) singular em nosso país.

2 O Desenvolvimento e a Avaliação de Competências por Meio de Situação-Problema

Segundo Macedo (2002), a situação-problema é um dos recursos utilizados para avaliação escolar e o desenvolvimento de competências. De acordo com Perrenoud (apud MACEDO, 2002), "as situações-problema caracterizam-se por recortes de um domínio complexo, cuja realização implica mobilizar recursos, tomar decisões e ativar esquemas". Além disso, as situações-problema criam desafios, destacam um fragmento de texto, solicitam comentário, propõem a análise, pedem para responder uma questão, elaborar proposta ou argumentar.

Embora possam ser propostos por artifício ou simulação, as situações-problema não são pretextos, mas uma delimitação de um contexto para reflexão, colocação de problema, conflito, raciocínio, tomada de posição, enfrentamento de uma situação, mobilização de recursos, nos limites do espaço, do tempo e dos objetos disponíveis para a realização da tarefa. Esse contexto, criado sob alterações que levam a pensar em outro nível, o de superação de obstáculos, tem por função desequilibrar, perturbar, problematizar. Baseado em Meirieu, 
Macedo afirma que a situação-problema é uma situação didática na qual se propõe ao sujeito a realização de uma determinada tarefa que ele não pode realizar sem ter adquirido uma aprendizagem precisa.

Pinheiro e Burini (2004, p. 28-37) sustentam que o aprendizado baseado em problemas deve integrar as práticas pedagógicas às diferentes disciplinas do currículo escolar. Acreditamos que isso se deva ao fato de ir desenvolvendo no aluno capacidades para resolver as propostas, afinal cada etapa da vida vai exigir do indivíduo uma forma diferente de raciocínio e a criação de situaçõesproblema, que contextualizem as aulas, pode conduzir o educando, para superar os desafios sugeridos pelas questões, capacitá-los para a produção de respostas ou a criação de melhores possibilidades para seu enfrentamento.

Durante a vida escolar as situações-problema referem-se aos conteúdos das disciplinas ou às áreas de conhecimento e valorizam situações que os professores acreditam ser significativas para serem discutidas, analisadas, avaliadas sobre determinada teoria ou disciplina. A situação-problema geralmente é organizada em torno da resolução de um obstáculo que não permite, ao aluno, formular conjecturas ou hipóteses. Ele tem a necessidade de elaborar ou de se apropriar de instrumentos intelectuais necessários para a busca da solução. A situação deve levar o aluno a investir conhecimentos previamente adquiridos, a um desafio intelectual, estimulando os conflitos sociocognitivos e sendo validados pelo modo de estruturação da própria situação.

Para gerenciar a execução dessa tarefa, os estudantes precisam, de um lado, ser mobilizados ao desafio, a ultrapassar obstáculos, superar perturbações e riscos, tomar decisões e, por outro, mobilizar as competências, ativar recursos cognitivos, gestuais e socioafetivos que os levem a ler, escrever, calcular, distinguir, argumentar, negociar, organizar etc. Dentro desse quadro, o professor tem o papel de favorecedor das condições para o desenvolvimento dos saberes, orientador e guia para a aquisição das formas culturais selecionadas como base do aprendizado para amplificar a formação do aluno. Desta forma, o educador deve ser um facilitador, orientador da aprendizagem e, além de um dinamizador da vida socioafetiva da sala de aula, buscar orientar esses aprendizes quanto às suas escolhas pessoal, escolar e profissional (PINHEIRO; BURINI, 2004, p. 29). 
Uma das funções da situação-problema, dentro do contexto escolar, é desafiar o educando a mobilizar recursos (as competências previamente desenvolvidas) para tomar decisões favoráveis ao cumprimento de metas e objetivos. A deficiência no desenvolvimento das competências - lingüística, lógico-matemática, espacial, musical, corporal-cinestésica, naturalista, pictórica, interpessoal, intrapessoal - pode ser fator inibidor para a articulação de informações, manifestação de medos, fantasias ou expectativas que levem a desconsideração de fatores relacionados ao problema proposto, isto é, acabam ocasionando uma desatenção que não contribui para uma diferenciação ou integração dos elementos disponíveis.

Já, no contexto de avaliação, a situação-problema com múltipla escolha é colocada como o problema, enunciada em forma de pergunta e com apenas uma das alternativas como sendo a correta, a que melhor expressa o que foi proposto. Para resolvê-la, o sujeito deve recorrer às suas competências de leitura, comparação, raciocínio etc. observáveis ao que o enunciado da questão formula, ou ao que recorre sobre o conteúdo a ser avaliado. Ao propor as questões da Prova do ENEM, o avaliador apóia-se sobre o assunto a ser testado, tendo em vista avaliar as competências desenvolvidas durante a formação escolar do avaliado. Para isso, o inscrito à Prova realiza operações de linguagem (SCHNEUWLY, 1994/2004) como, por exemplo, de interpretação, análise, comparação, abstração, generalização que o conduz a reconhecer, entre as alternativas oferecidas, a que melhor corresponde ao que foi perguntado.

Os enunciados - que a partir de agora chamaremos de "enunciados de comando" devido à presença marcada de um enunciador específico com intenções e objetivos previamente delineados - são sinalizados, marcados por indicadores, aspectos destacáveis no seu texto e que levam o enunciatário a conjecturar pensamentos, idéias, representações, lembranças, raciocínios, sentimentos etc. Juntos, esses indicadores (tanto do enunciado de comando quanto do próprio sujeito) é que propiciarão a tomada de decisão, julgamento sobre o que está sendo perguntado e as alternativas disponíveis em que apenas uma será a correta. O que possibilita a conclusão ou tomada de decisão, nesse contexto de raciocínios, julgamentos, interpretação de informações, é o importantíssimo processo de inferência. Para Macedo (2002, p. 122), "uma boa questão 
deve propor um percurso entre uma situação de partida, que corresponde à proposição do enunciado, até o ponto de chegada, que corresponde à escolha da alternativa, suposta pelo avaliado como a que melhor representa a resposta correta".

A tomada de decisão, mobilização de recursos e saber agir caracterizam e consolidam as competências adquiridas ao longo da vida escolar, pois permitem a construção, coordenação e articulação de esquemas e pensamentos que nada mais são do que capacidades de linguagem que os indivíduos têm para atuar de maneira ativa e com sucesso na sociedade, enfrentando os desafios e questões propostas pela diversidade sociocultural que têm que enfrentar.

A escola, como lugar de reunião dos conhecimentos de uma cultura, reúne como informação, explicação ou regularidade aquilo que considera relevante para os seres humanos, os seres vivos ou a natureza, porém esses conhecimentos têm que vir articulados com a questão da competência. No que tange à mobilização de recursos afetivos e cognitivos dos alunos, a escola tem a incumbência de construir e coordenar perspectivas na direção pretendida, nesse caso, os documentos oficiais cumprem essa função, a de estabelecer os parâmetros para o ensino, definir metas, objetivos, propósitos para a ação pedagógica.

A competência para o agir do aluno pode ser caracterizada, portanto, como "saber dizer", como comunicar, explicar, compreender, racionalizar, organizar, justificar, embasar para que algo possa realizar-se enquanto expressão do pensamento, representação, compreensão ou sentido. Macedo (2002) preconiza que, no desenvolvimento de competências, os verbos abstrair, generalizar, transferir, aprender, recorrer, mobilizar, esquematizar são condições fundamentais para o alcance de valores, regras, lógica etc.

A competência em relação à situação-problema se configura como a realização de uma tarefa em que o indivíduo deve mobilizar recursos, ativar esquemas e tomar decisões. Com essas ações preserva informações do passado para organizar o presente e está capacitado a desafiar o desconhecido, diferenciar e integrar as partes e o todo que estruturam e organizam suas interações com o mundo e consigo mesmo.

Os PCNEM são estruturados em torno de três eixos de ensino: representação e comunicação; investigação e compreensão; 
contextualização sócio-cultural. Já o ENEM visa avaliar a aquisição dessas competências por meio do desempenho do desenvolver inscrito. Dentro destes temas (ZIRONDI E NASCIMENTO, 2005), buscase:

- Desenvolver a competência interativa: Identificar intenções e situações de uso da língua falada e escrita; relacionar texto e contexto de uso; Distinguir contextos; adequar o uso ao contexto; escolha de variante adequada a situação de uso; identificar níveis de linguagem; analisar julgamentos e opiniões.

- Desenvolver a competência textual: função da intertextualidade; protagonista do discurso; recursos expressivos relacionados aos textos e seu contexto; confrontar opiniões sobre diferentes manifestações da linguagem verbal.

- Desenvolver a competência gramatical: distinguir gramática normativa e descritiva a partir da adequação ou não-adequação a situações de uso; considerar as diferenças entre oral e escrito; a gramática vista em elaboração e revisão constantes; distinguir gramática normativa e descritiva a partir da adequação ou nãoadequação às situações de uso; considerar as diferenças entre oral e escrito; a gramática vista em elaboração e revisão constantes

- Avaliar se houve a aquisição das seguintes competências: domínio de linguagens; compreensão de fenômenos; resolução de situação-problema; construção de argumentação; elaboração de proposta.

A Matriz de competências foi desenvolvida como forma de estruturação do ENEM, como escopo de definir seus pressupostos e delinear suas características operacionais. Com isso, pressupõe-se colaboração, complementaridade e integração entre os conteúdos das diversas áreas do conhecimento presentes nas propostas curriculares e considera-se que, conhecer, é construir e reconstruir significados continuamente, mediante o estabelecimento de relações de múltipla natureza, individuais e sociais.

Para avaliar as competências requeridas pelos PCNEMs e desenvolvidas durante a vida escolar, o ENEM, desenvolvido pelo 
INEP ${ }^{2}$ (Instituto Nacional Pesquisas Educacionais Anísio Teixeira, órgão criado pelo governo em 1934, tem como objetivo promover inquéritos e pesquisas relacionados às doutrinas e técnicas pedagógicas), tem como sujeito enunciador da Prova o próprio órgão que, em situação e propósito avaliativo específicos, comanda a circunstância produzindo por meio de enunciados de comando e de situações-problema o "ambiente" perfeito para cumprir suas metas e objetivos (avaliar a qualidade do ensino-aprendizagem e a aquisição das competências necessárias para o mundo do trabalho e exercício da cidadania).

O "comando" dado pelo enunciador no enunciado funciona como uma questão-estímulo (MENEGASSI, 2003, p. 55) oferecida ao aluno com objetivo de levá-lo à finalidade da proposição em relação ao enunciado; a inferir sobre o texto (ou fragmento) de texto do gênero utilizado como recurso para avaliação; reconhecimento da disciplina que preferencialmente esse texto circula; possíveis locutores e/ou interlocutores desses textos.

\section{Os Enunciados de Comando do ENEM}

Compactuamos com Rosa (2003, p. 11) sobre o fato de a língua ser um processo de interação verbal, sociocultural e historicamente determinado e variável de acordo com o tempo, comunidade, esfera social, interesses e objetivos específicos. Sob essa alegação, "catalogamos" a Prova do ENEM como uma prática sóciocomunicativa na qual a linguagem (texto) a caracteriza como um gênero textual devido aos seus aspectos constitutivos (ZIRONDI; NASCIMENTO, 2006) relativamente estáveis que nos permitem diferenciá-lo e determiná-lo em relação a outros gêneros. Segundo Adam (BONINI, 2005), os gêneros textuais são formados por "esquemas lingüísticos", isto é, seqüências textuais que exercem um papel de destaque na organização infra-estrutural mais geral de um texto, uma vez que tem por função estruturar linearmente o seu conteúdo temático.

Como já mencionamos anteriormente, o gênero textual de avaliação, a Prova do ENEM, não se configura como os textos standards, isto é, textos nucleares, menos heterogêneos, mas sim, por

\footnotetext{
${ }^{2}$ Informações contidas no site $<$ http://www.inep.gov.br $>$.
} 
uma estruturação complexa que torna o seu conteúdo "atravessado" por outros textos de outros gêneros. No entanto, há a possibilidade de identificarmos um "esqueleto", que sustenta esses textos utilizados pelo enunciador para garantir o seu propósito comunicativo. A essa "armadura" atribuímos o nome de "enunciado de comando", pois é nele que ocorre uma ancoragem enunciativa do gênero e permite identificarmos a voz de comando do enunciador. Portanto, a partir do enunciado de comando, podemos "visualizar" a planificação efetuada pelo enunciador e, desta forma, compreender os processos lingüísticotextual do funcionamento sócio-discursivo de sua linguagem. Ou seja, entender que a ação de linguagem instaurada no texto objetiva, de maneira geral, orientar as pessoas para a realização de uma determinada tarefa, como é o caso das situações-problema da Prova do ENEM.

Portanto, a seqüência discursiva dos enunciados de comando, esquema cognitivo utilizado pelo(s) produtor(es) do texto, se caracteriza por uma ação de linguagem injuntiva. ${ }^{3}$ As ações de linguagem funcionam como uma forma de agir sobre o mundo e sobre os nossos interlocutores e, em contrapartida, são também um modo de representação do mundo. Dentro dessa perspectiva interacional, de um lado, o enunciador prepara terreno para avaliar futuramente um comportamento observável (no caso da Prova o acerto ou não da questão) e, de outro, o enunciatário, que terá que estabelecer as relações entre os conceitos dos fenômenos que o levará ao julgamento dessa ação (a realização da atividade). O enunciado de comando seria, então, a nosso ver, a parte "mais concreta" do texto, componente do discurso propriamente dito, organizador e esquematizador do gênero. O texto em si, em sua estrutura composicional, seria a parte "abstrata" (aquilo que é objeto da lingüística textual).

A Prova do ENEM vem planejada por um sujeitoesquematizador pertencente a uma formação discursiva institucional (pertencente e elaborada pelos proponentes da Política Educacional) cujo discurso apresenta um estatuto dialógico ao interagir com os discursos dos inscritos, geralmente alunos que terminaram o Ensino

\footnotetext{
${ }^{3}$ Segundo Adam (apud Bronckart, Bonini e outros), a injunção se caracteriza como uma das categorias que são definidas por unidades lingüísticas específicas como as da narração, descrição, argumentação, explicação, diálogo e injunção.
} 
Médio, comandando-os e instruindo-os por meio dos enunciados de comando que determinam quais capacidades de linguagem (capacidades de ação, discursiva ou lingüístico-discursiva) devem ser acionadas para cumprir os objetivos não só de cada ação de linguagem isolada (resolução de cada uma das situações-problema), como também, da ação de linguagem global, maior, que justifica toda a realização e objetivação da ação (os resultados finais da Prova vistos sobre seu aspecto coletivo e não mais individual).

Numa releitura a partir de Adam, Bronckart (1999, p. 237) sustenta que a organização lingüística seqüencial, em algumas situações, pode aparecer com o objetivo de "fažer ver ações mais do que objetos ou situações". O agente produtor visa a fazer agir seu destinatário, direcionando-o a uma resposta/reação já esperada, portanto, ocorre a estruturação seqüencial injuntiva em que o discurso se apresenta como problemático ou contestável, esquematizado de forma a organizar o conteúdo temático refletindo as etapas para os procedimentos de raciocínio lógico natural.

Um gênero textual possui o seu conteúdo temático planificado por uma ou mais de uma seqüência ao mesmo tempo. Contudo, embora o gênero seja heterogêneo quanto à sua planificação seqüencial, uma das seqüências apresenta-se, freqüentemente, como preponderante sobre as demais. O gênero textual Prova do ENEM, por ser um gênero elaborado sob condição complexa e heterogênea, pode ser identificado como seqüência relevante a injuntiva, tornando o texto da Prova também injuntivo. Segundo Heurley (apud ROSA, 2003 , p. 16), o processo que rege o funcionamento do texto injuntivo pode ser considerado como bipolar: em um pólo encontram-se o(s) agente(s) produtor(es) que detêm um saber especifico a ser engendrado; em outro pólo, está/ão o(s) destinatário(s), aquele(s) que "utilizará/ ão", uma única pessoa ou uma equipe homogênea de indivíduos ou, ainda, um grupo extremamente heterogêneo que executará a tarefa (no caso do ENEM, fará parte do teste de avaliação um grande grupo heterogêneo de participantes inscritos que se utilizará da leitura, compreensão, execução das atividades de redação e resolução das situações-problema).

A seqüência injuntiva, então, é utilizada como recurso pelo produtor para "fazer agir" o seu destinatário. O enunciador, pressupondo que seu interlocutor está apto para realizar a tarefa 
(aprendizagem desenvolvida durante a formação escolar), explicita através da sua ação lingüística o "como fazer". Rosa (2003, p.16), em suas reflexões sobre a seqüência injuntiva menciona que "em face de um macro-objetivo acional (ação principal) a se executar, o enunciador apresenta uma série de comandos (ações secundárias) que formam um plano de execusão para que aquele macro-objetivo seja atingido". $\mathrm{Na}$ Prova do ENEM tem-se o macro-objetivo acional - avaliar as capacidades de linguagem adquiridas e desenvolvidas por meio das competências sugeridas pelos PCNEM, e para realizar essa macroação é preciso que o leitor do texto siga um plano de comandos explicitado verbalmente, desenvolvendo, assim, uma série de microações referentes à resolução das situações-problema.

Nossa investigação centraliza-se, portanto, na análise dos elementos lingüísticos que compõem justamente o enunciado do fazer agir. A consolidação das competências exigidas é intencionalmente comandada pelos verbos que expressam ações e operações do pensamento, tais como os que mobilizam, articulam, colocam em ação, os quais deslocam para a prática valores, conhecimentos e habilidades mobilizadas pelas capacidades de linguagem adquiridas ao longo da formação do aluno. Essas unidades lingüísticas representam um conjunto de informações e instruções organizadas, as quais permitirão executar o mais diretamente possível as ações orientadas.

De acordo com Bronckart (1999, p.156), "as propriedades gerais da linguagem humana podem ser identificadas por abstraçãogeneralização a partir das diferentes formas de realização observáveis em línguas naturais". O enunciador seleciona as informações e as organiza numa unidade de texto significativa tendo em vista os objetivos de interação pretendidos com o enunciatário e o domínio de determinados conteúdos atribuídos as sua(s) capacidade(s) lingüística(s). $\mathrm{Na}$ interação emergente na prova do ENEM, o enunciador propõe uma questão ao aluno e a resposta esperada está no verbo constante nas locuções da instrução, contidos nos enunciados de comando, ex: $e ́$ correto afirmar, está empregado...ocorre em; deve ser localizada; têm em comum; equivale a; é de; torna explicita; podem ocorrer, foi no; pode ser justificado; está correto... A enunciação das questões não exige necessariamente a presença de um autor, nem ter uma referência precisa ao espaço-tempo da 
produção e por isso consideramos esse tipo de discurso da ordem do expor. ${ }^{4}$

Entretanto, o diálogo que se realiza nesse tipo de enunciado é de certa forma "mascarado", isto é, há a implicação de dois agentes que alternam os turnos de fala a cada questão, mas não são explicitamente identificados. Primeiro, o enunciador abre o turno de fala exigindo uma atitude responsiva de seu destinatário (uma resposta à alternativa). Há, portanto, a implicação dos parâmetros físicos da ação de linguagem, embora, não haja unidades dêiticas explicitas que remetam diretamente aos agentes em interlocução e às coordenadas gerais desse mundo discursivo criado. Colocado próximo ao mundo ordinário de ação de linguagem, o mundo semiotizado do conteúdo temático, mobilizado nessa interação, remete diretamente aos interactantes (dêixis externa implícita) e a organização desse segmento em relação à estrutura da ação em curso. Portanto, o tipo de discurso que caracteriza esse tipo de texto (enunciado) é o discurso interativo (BRONCKART, 1999). ${ }^{5}$

O conteúdo de um texto é "constituído pelos conhecimentos disponíveis na memória dos agentes" (BRONCKART, 2004). Portanto, o leitor parte de representações da sua memória, que precedem ao texto, e que servem como base, ponto de partida, para que adapte, acrescente, modifique, reconheça, reproduza etc em um novo tipo de texto ou gênero. Esse conteúdo "referencial" acionado pelo leitor é mobilizado pela capacidade de ação já adquirida e que, a cada leitura, evolui num processo progressivo de desenvolvimento.

${ }^{4}$ Bronckart (1999, p. 153-154) pondera que os mundos discursivos são da ordem do NARRAR e da ordem do EXPOR. No primeiro, o mundo discursivo é situado em um "outro lugar", as representações mobilizadas como conteúdo refere-se a fatos passados, a fatos futuros e plausíveis ou puramente imaginários. Já, no segundo, os fatos são apresentados como sendo do mundo ordinário dos protagonistas da interação de linguagem: não são narrados, mas mostrados, ou expostos.

${ }^{5}$ Bronckart (1999) atribui ao mundo do expor dois tipos básicos de discurso, discurso interativo e discurso teórico e para o mundo do narrar, o relato interativo e a narração. De acordo com ele, no discurso interativo, o texto está articulado a uma situação de ação de linguagem que implica dois agentes que alternam tomadas de turno em um espaço-tempo comum. (ver cap. 5: Os tipos de discurso, p. 137-216) 
Observemos a questão 7 (sete) da Prova do ENEM de 2005. Ela mobiliza a capacidade de ação do aluno em reconhecer em qual situação a interação ocorre. Para executar essa tarefa, o aluno deverá recorrer à capacidade de ação em inferir sobre situações históricas, de convívio social ou situacional. Para resolver essa situaçãoproblema, a escola deverá ter cumprido seu papel que é o de desenvolver a competência interativa no aluno, porque, afinal, essa é a proposta disseminada pelos PCN e PCNEM e está diretamente atrelada às competências avaliadas pelo ENEM: possibilitar a compreensão de fenômenos, nesse caso, as relações pessoais e o avanço tecnológico (interação e o meio).

7 A situação abordada na tira torna explícita a contradição entre a

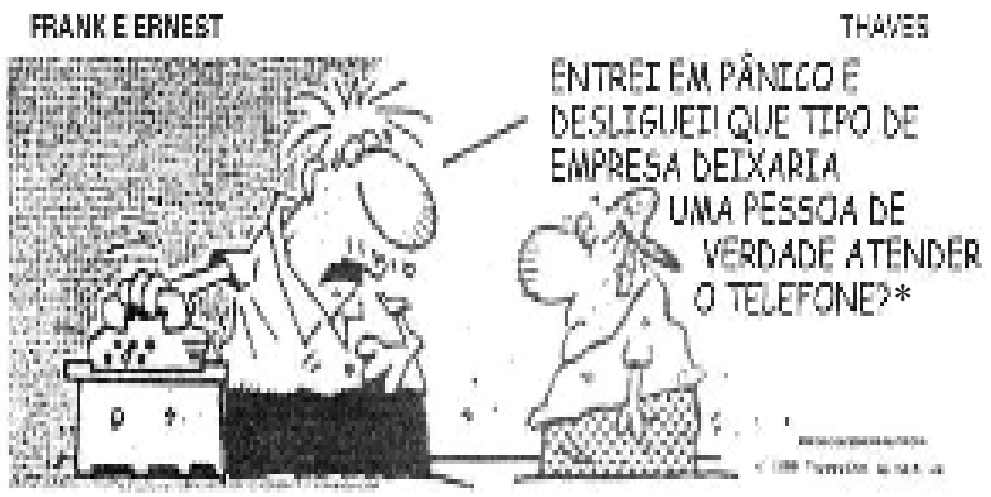

* (Entrei em pânico e desliguei! Que tipo de empresa deixaria uma pessoa de verdade atender o telefone?)
(A) relações pessoais e o avanço tecnológico.
(B) inteligência empresarial e a ignorância dos cidadãos.
(C) inclusão digital e a modernização das empresas.
(D) economia neoliberal e a reduzida atuação do Estado.
(E) revolução informática e a exclusão digital.

Agora, analisemos o enunciado de comando dessa questão: "A situação abordada na tira torna explícita a contradição entre a:". O enunciado de comando fornece "pistas" para aluno resolver a situação-problema sob dois aspectos convergentes: o 
primeiro aponta para aspectos do plano textual global da questão. "A situação abordada na tira [...]" apontando para o texto do gênero da esfera artística utilizado como recurso para a avaliação (a tira em si) e, “[...] a contradição entre a:" o texto formulado pelo enunciador como recurso e objetivo para avaliação. O segundo aspecto "[...] torna explicita [...]" remete à ação do aluno quanto à tarefa (a escolha de uma das alternativas da múltipla escolha).

Observem este outro exemplo da mesma prova (questão 30):

30

As cobras estão entre os animais peçonhentos que mais causam acidentes no Brasil, principalmente na área rural. As cascavéis (Crotalus), apesar de extremamente venenosas, são cobras que, em relação a outras espécies, causam poucos acidentes a humanos. Isso se deve ao ruído de seu "chocalho", que faz com que suas vítimas percebam sua presença e as evitem. Esses animais só atacam os seres humanos para sua defesa e se alimentam de pequenos roedores e aves. Apesar disso, elas têm sido caçadas continuamente, por serem facilmente detectadas. Ultimamente os cientistas observaram que essas cobras têm ficado mais silenciosas, o que passa a ser um problema, pois, se as pessoas não as percebem, aumentam os riscos de acidentes.

A explicação darwinista para o fato de a cascavel estar ficando mais silenciosa é que

(A) a necessidade de não ser descoberta e morta mudou seu comportamento.

(B) as alterações no seu código genético surgiram para aperfeiçoála.

(C) as mutações sucessivas foram acontecendo para que ela pudesse adaptar-se.

(D) as variedades mais silenciosas foram selecionadas positivamente.

(E) as variedades sofreram mutações para se adaptarem à presença de seres humanos.

O enunciado de comando "A explicação darwinista para o fato de a cascavel estar ficando mais silenciosa é que", da 
mesma forma que o anterior, organiza elementos lingüísticos “A explicação darwinista [...]" que remetem a textos do gênero da esfera cientifica utilizado como recurso pelo enunciador para avaliar um conhecimento específico, nesse caso, o conhecimento da teoria darwinista (discurso internalizado pelo aluno, provavelmente, nas aulas de biologia - a que se refere a teoria darwinista?) e que terá que relacionar com esse texto, portanto, não foi explicitado aqui pelo autor. "Para o fato de a cascavel estar ficando mais silenciosa [...]" remete para o texto utilizado como recurso para avaliação, e a locução verbal "estar ficando" funciona como uma pista para o aluno inferir sobre o texto. O "[...] é [...]" seria, a nosso ver, o elemento que indica a ação a ser executada (escolha de uma das alternativas) que o "[...] que" estabelece como certa em relação as outras. Para resolucionar essas questões, o aluno precisa mobilizar suas capacidades discursivas, adquiridas ao longo de sua formação, por meio de discursos dispostos no intertexto.

Já, nesta outra questão (19):

As questões 19 e 20 referem-se ao poema.

ADANÇAE A ALMA

A DANCA? Não é movimento,

súbito gesto musical.

É concentração, num momento,

da humana graça natural.

No solo não, no éter pairamos,

nele amaríamos ficar.

$A$ dança - não vento nos ramos:

seiva, força, perene estar.

Um estar entre céu e chão,

novo dominio conquistado,

onde busque nossa paixão

libertar-se por todo lado...

Onde a alma possa descrever

suas mais divinas parábolas 
sem fugir à forma do ser,

por sobre o mistério das fábulas.

(Carlos Drummond de Andrade. Obra completa. Rio de Janeiro:

Aguilar, 1964. p. 366.)

19 A definição de dança, em linguagem de dicionário, que mais se aproxima do que está expresso no poema é

(A) a mais antiga das artes, servindo como elemento de comunicação e afirmação do homem em todos os momentos de sua existência.

(B) a forma de expressão corporal que ultrapassa os limites físicos, possibilitando ao homem a liberação de seu espírito.

(C) a manifestação do ser humano, formada por uma seqüência de gestos, passos e movimentos desconcertados.

(D) o conjunto organizado de movimentos do corpo, com ritmo determinado por instrumentos musicais, ruídos, cantos, emoções etc.

(E) o movimento diretamente ligado ao psiquismo do indivíduo e, por conseqüência, ao seu desenvolvimento intelectual e à sua cultura.

No enunciado "A definição de dança, em linguagem de dicionário, que mais se aproxima do que está expresso no poema é" temos "A definição de dança [...]" remetendo para as questões de múltipla escolha; “[...] em linguagem de dicionário [...]” remetendo para conhecimento previamente adquirido (conhecimento lingüístico - língua culta/técnica - e discursivo - finalidade expressiva especifica de uma linguagem: capacidade lingüístico-discursiva); “[...] que mais se aproxima [...]" relaciona os termos "a linguagem com o que está expresso no poema”; “[...] do que está expresso no poema [...]" remetendo para o texto do gênero artístico utilizado pelo enunciador para avaliar a competência do aluno em reconhecer o valor semântico e contextual dessas unidades lingüística e; “[...] é” se referindo aos itens de múltipla escolha (encaminhamento para a execução da atividade pelo aluno).

O enunciador do enunciado de comando funciona como um "maestro" a orquestrar as ações do candidato. Ora se refere ao texto do gênero utilizado como recurso para avaliar; ora às questões 
de múltipla escolha; ora para relacionar um elemento a outro; ora para explicitar claramente ao aluno que deve inferir sobre conhecimentos previamente adquiridos e externos ao texto. O que vale reforçar é que as ações do enunciador são intencionais, ao fazer isso consegue administrar o raciocínio do aluno para que ele exercite e empregue as capacidades de linguagem (SCHNEUWLY, 1994/2004), que adquiriu durante sua formação escolar, avaliando desta forma se as competências sugeridas pelos documentos oficiais estão sendo eficientes nas propostas pedagógicas se estão sendo ensinadas/aprendidas de maneira eficaz por professores e alunos.

\section{Considerações Finais}

Refletindo sobre as relações sócio-discursivas e pragmáticas que regem a ação de linguagem do gênero textual de avaliação Prova do ENEM, averiguamos que seu texto de base ("plano textual global") é planificado predominantemente pela seqüência injuntiva. A escolha e o uso da injunção pelos enunciadores da Prova não se dá de maneira aleatória, estão atreladas e intimamente relacionadas com os objetivos comunicativos e finais (avaliar se as competências são ensinadas de maneira eficaz e se atendem às necessidades da escola e dos alunos) programados e almejados pelo enunciador. O agente-produtor do texto da Prova arquiteta "fazer agir" seu destinatário em determinada direção por meio dos enunciados de comando.

Os inscritos, geralmente alunos que acabaram de concluir o Ensino Médio, interpretam esses comandos como uma "ordem", mas que para executá-la dependem dos conhecimentos adquiridos no decorrer de sua vida escolar. Se bem trabalhados, os conteúdos sugeridos pelos documentos oficiais para realização das tarefas pedagógicas, desenvolverão nos alunos competências para o uso eficaz da linguagem, acionadas tanto nas atividades de produção quanto nas de compreensão pela leitura; se não, esses alunos apresentarão um déficit na aprendizagem e, conseqüentemente, problemas para as atividades sócio-interativas da linguagem.

A metodologia que utilizamos em nossas análises nos conduziu a uma conclusão bipolar em relação ao Exame e aos efeitos pretendidos em seus destinatários, o que nos leva a considerá-la de 
grande eficácia e relevância diante da teoria adotada, uma vez que esta tem por primazia a função social do gênero de texto em questão. Em um pólo está o aluno (inscrito) cujo papel social principal dentro desse quadro seria o de testar e avaliar as suas próprias capacidades de linguagem (capacidade de ação, capacidade discursiva; capacidade lingüísticodiscursiva), isto é, fazer uma auto-avaliação, individual e intransferível a outro sujeito, de suas próprias potencialidades. Em outro pólo estariam os avaliadores, cuja função reside na tarefa de "mensurar" a qualidade do ensino em relação aos conteúdos sugeridos pela política educacional para desenvolver as competências nos alunos mediante os programas pedagógicos fornecidos pelo ensino, o que significa a testagem e avaliação por meio do ENEM das competências requeridas pelos PCNEM.

\section{Referências Bibliográficas}

BAKHTIN, Mikhail M.. Estética da criação verbal. Trad. Maria Ermantina G. G. Pereira. 2. ed. São Paulo: Martins Fontes, 1997.

BRASIL. Ministério da Educação e do Desporto. Secretaria de Educação. Parâmetros Curriculares Nacionais. Língua Portuguesa, Brasília: 1997.

BRONCKART, Jean Paul. Revista Virtual de Estudos da Linguagem - REVEL, a. 4, n. 6, mar. 2006a. (tema: Estudo do texto e discurso).

Atividades de linguagem, discurso e desenvolvimento humano. Campinas: Mercado das Letras, 2006b.

Os gêneros de textos e os tipos de discurso como formatos das interações propiciadoras de desenvolvimento. In: Atividade de linguagem, discurso e desenvolvimento humano. Trad. Anna Rachel Machado e Maria de Lourdes Meirelles Matencio. Campinas: Mercado de Letras, 2006c.

Atividades de linguagem, textos e discurso: por um interacionismo sócio-discursivo. Trad. Anna Raquel Machado; Péricles Cunha. São Paulo: EDUC, 1999. 
.; MACHADO, Anna Rachel. Procedimentos de análise de textos sobre o trabalho educacional. In: MACHADO, Anna Rachel (Org.). O ensino como trabalho: uma abordagem discursiva. Londrina: Eduel, 2004.

BONINI, Adair. A noção de seqüência textual na análise pragmáticotextual de Jean-Michel Adam. In: MEURER, J. L.; BONINI, Adair; MOT'T-ROTH, Desirée (Orgs.). Gêneros-teorias-métodos-debates. São Paulo: Parábola, 2005.

INSTITUTO NACIONAL DE ESTUDOS E PESQUISAS EDUCACIONAIS ANÍSIO TEIXEIRA. Disponível em: <http:// www.inep.gov.br>. Acesso em: 20 maio 2005.

MACEDO, Lino de. Situação-problema: forma e recurso de avaliação, desenvolvimento de competências e aprendizagem escolar. In: PERRENOUD, Philippe; THURLER, Mônica Gather et al. As competências para ensinar no século XXI: a formação dos professores e o desafio da avaliação. São Paulo: Artmed, 2002.

MENEGASSI, Renilson José. Professor e a escrita: a construção de comandos de produção de textos. Trabalhos em Lingüística Aplicada, Campinas, n. 42, p. 55-79, jul./dez. 2003.

NASCIMENTO, Elvira Lopes; ZIRONDI, Maria Ilza. Prova do ENEM: um gênero desencadeador de novas ações pedagógicas? In: ENCONTRO CIENTÍFICO DO CURSO DE LETRAS, 3., 2005, Rolândia. Anais... Disponível em: <http://www.faccar.com.br/ desletras/hist/2005_g/index.html>. Acesso em: 24 jul. 2006.

PERRENOUD, Philippe; THURLER, Mônica Gather et al. As competências para ensinar no século XXI: a formação dos professores e o desafio da avaliação. São Paulo: Artmed, 2002.

PINHEIRO, A. C. da F. Bragança; BURINI, Elaine R. V. O ensino por competências como metodologia didática para aprendizado baseado em problemas. Revista de Educação Continuada Momento do Professor - A questão das competências e o Ensino, São Paulo, a. 1, n. 5, p. 28-37, set./dez. 2004. 
ROSA, Adriana L. T. da. No comando, a seqüência injuntiva! In: DIONIZIO, Ângela Paiva; BEZERRA, Normanda da Silva (Orgs). Tecendo textos, construindo experiências. Rio de Janeiro: Lucerna, 2003.

SCARAMUCCI, Matilde V. R. Efeito retroativo da avaliação no ensino/aprendizagem de línguas: o estado da arte. Trabalhos em Lingüística Aplicada, Campinas, 2004.

SCHNEUWLY, Bernard. Gêneros e tipos de discurso: considerações psicológicas e ontogenéticas. In:

Gêneros textuais na escola. Trad. e org. Roxane Rojo; Glaís Sales Cordeiro. Campinas: Mercado das Letras, 2004.

ZIRONDI, Maria Ilza; NASCIMENTO, Elvira Lopes. Prova do ENEM: o impacto de um gênero textual no ensino médio. In: SIMPÓSIO INTERNACIONAL DE ESTUDOS DE GÊNEROS TEXTUAIS, 3., 2005, Santa Maria. Anais... Santa Maria: 2006. 